\title{
The Ageing Population and the Challenges of Health Management: A Study of Retirees of Public Institutions in South East Nigeria
}

\author{
Samuel, O. Okafor ${ }^{1, *} \&$ Christopher, O. Ugwuibe ${ }^{2}$ \\ ${ }^{1}$ Department of Sociology \& Anthropology (Demography), University of Nigeria, Nigeria \\ ${ }^{2}$ Department of Public Administration \& Local Government, University of Nigeria, Nigeria \\ *Correspondence: Department of Sociology \& Anthropology (Demography), University of Nigeria, Nigeria. E-mail: \\ samuelokey200@gmail.com
}

Received: January 9, 2020 Accepted: January 19, $2020 \quad$ Online Published: January 22, 2020

doi:10.5430/wjss.v7n1p31 URL: https://doi.org/10.5430/wjss.v7n1p31

\begin{abstract}
While life expectancy will continue to improve owing to the domestic humanitarian improvement, proxy-policy influence on the sub-Saharan African nations [Nigeria included] by the United Nations and other developed nations, the ageing population will continue to increase making it more or less policy imperative among the nations within this region. Among other things, public health policy occupies the most important position in the web of policy approach to the needs and care for the aged. In the light of the above, the present paper investigated the realities of public health policy outcome [1988 to 2016], as it affects the ageing populations via public health facilities and health packages for the aged. 600 retirees of public institutions from southeast Nigeria were involved in the study, which adopted survey design and modified random sampling techniques. In view of the substantive issues of the study, less than $25 \%$ of the respondents go for regular medical checkups and self-health maintenance, more than $80 \%$ depended on self-support for medical upkeep; the regression model adopted in the study proved [p $<.05]$, the factors affecting regular health upkeep and satisfaction with services at the public health facilities among the retirees.
\end{abstract}

Keywords: ageing population, Nigerian Public Health Policy; public health facilities, health services, retirees

\section{Introduction}

In the wake of improvement in life expectancy across the globe, ageing has become one of the issues of the century both in principle and in practice among the nations of the globe (Kalache, Barreto \& Keller, 2005; United Nations, 2005; Velkoff \& Kowal, 2005; Max, 2018). Except in extreme cases such as war and epidemiological disasters, ageing and life expectancy is set to sustainably advance among the nations of the globe, putting nations under pressure to evaluate their social policies from time to time to accommodate the unfolding needs of the aged and the inalienable responsibilities of the society towards the aged (Bramucci \& Erb, 2007; Wells, 2005; Lipman, Lubell, \& Salomon, 2012).

Ageing and its accompanying responsibilities have become a reality in most developed nations in principle and practice, and in principle, perhaps, among the developing nations. While in principle for the sake of the present work, ageing is appearing as inexorable fact based on empirical justification, in practice, ageing is being adapted into as a form of social change requiring a pragmatic approach. Among the developed nations where policy structures are pragmatic and flexible from time to time to accommodate the recent development in every aspect of human existence, ageing has become a practice in policy structures and development (Swedish National Institute for Public Health, 2006; Pew Research Center, 2014; Lee \& Wolf, 2014). However, among most developing nations, ageing still appears as scientific principles beyond the individual and group ignorance but lacks recognition in social policy structure of the time (Joshi, 2006; Ferreira, 2005; Mudiare, 2013). This can be attributed to a host of challenges facing the developing nations such as insensitivity to globally relevant issues and scientific information (Gureje, Lola, Ebenezer,\&Oladapo, 2008), bureaucratic bottleneck (Adebowale, Atte, \& Ayeni, 2012), dogmatic approach to policy formulation, implementation and evaluation (Aboderin, 2007; Kaneda, Lee, \& Pollard, 2011), bias towards social policies majorly affecting the minors and "economic-liability-members of the society", etc. 
From the pages of scientific documentation (World report on ageing and health, 2015; de Carvalho, Epping-Jordan, Pot, Kelley, Toro, Thiyagarajan, \& Beard, 2017; WHO, 2015), ageing has become a current and future reality, which must be accorded attention among nations. In sub-Saharan Africa for instance, the percentage of the aged currently and the projected future percentage of the aged based on the globally acknowledged sources (WHO, 2010; Aboderin, 2015; Center for Disease Control and Prevention, 2015), simply reveals the necessity for objective inclusion of ageing in the structures of social policies in this region especially, that of health policy. Contrary to this, social policies in sub-Saharan Africa, where they technically acknowledged the socioeconomic and health situations peculiar to the aged, have done so as appendages vulnerable to an omission by the policy implementers.

The plight of the aged cannot be overemphasized owing to voluminous data pointing to their vulnerabilities ranging from health complications (Davis, McMahon, Pichora-Fuller, Russ, Lin, Olusanya, Chadha, \& Tremblay, 2016; Cesari, Prince, Bernabei, Chan, Gutierrez-Robledo, Jean-Pierre, Morley, Ong, Manas, Sinclair, Won, \& Vellas, 2016), abuse (Pillemer, Burnes, Riffin \& Lachs, 2016), social stigma (Woolf, March, Officer, Cross, Briggs, Hoy, Riera, \& Blyth, 2016; Akpan \& Umobong, 2013), technical omission of their peculiarities in the social policies of most sub-Saharan African nations (Aboderin \& Beard, 2015), to economic implication of their condition, usually viewed from negative perspective [as liabilities] by the policymakers, society, communities and family members (Baer, Bhushan, Taleb, Vasquez \& Thomas, 2016; Ong, 2016). Due to onward-capitalistic tendency dominating the nations of the sub-Saharan Africa of which Nigeria is one of them, the aged are simply viewed as liabilities rather than assets compared to the youth and the infants such that anything spent in taking care of them appears as "open-ended expenditure" rather than investment for returns. This now dominates the understanding of the majority of the members of the society surrounding the aged, especially with the widespread of a high level of individualism among the nations in question. In the end, caring for the aged become more jeopardized as days go by.

In Nigeria in particular, the aged seem to be technically ignored in the social policies. This appears in different forms such as the deliberate omission of the aged in some aspects of social policy such as health, economic policy, labour, education, information, arts and culture, environment, etc. Nonetheless, in the social policies, where they observed the peculiarities affecting the aged, they do so in an unserious manner, such that it appears as appendage or subject to the survival of the fittest. Specifically, in the Nigerian national health policy over the decades of its existence (at least from 1988 to 2016), the elderly and their peculiar health conditions have not reflected as one of the major thrusts of the policy even though the aged have been there and continue to grow in response to the improved life expectancy in the country.

One of the outcomes of the public health policy in Nigeria is the way the public health facilities are organized both in structure and administration. This reflects on the way certain categories of the members of the society are handled while seeking for health services. For instance, in the structural arrangements of the public health facilities, there are indices of preferences for infants and pregnant women. Equally, health conditions, which are peculiar to the expectant mothers and the children, have their specifications in terms of health services subsidies and infrastructural arrangements. However, certain conditions, which characterize the ageing population health needs, currently, have no specific recognition both in the infrastructural and administrative discharge of health services in the public hospitals.

The aged needs special attention in the hospital setting and specialists on their conditions. Among other things, the aged who are mostly the population, which have retired from public life, expect support in every area of their lives including health maintenance. The hospital facilities for the care of the aged are different from the general hospital facilities to accommodate their conditions. Equally, there is a number of health challenges such as Alzheimer's, dementia, etc. that majorly affect the aged. These health challenges require specialists as well as special facilities. However, the current situation of the public health facilities and policy in Nigeria is in doubt in meeting these expectations.

To be specific, the understanding of the impact or implication of the dominant health policy as it affects the ageing population can be anchored on the retirees of the public sector. Among other things, there is some level of advanced and consistent documentation of the socioeconomic histories surrounding these fellows. While the inconsistent population documentation and ignorance of public health issues and existing government policies among the general Nigerian population can be a hitch to research agenda on ageing population and health, by extrapolation, the retirees of the federal government institutions can be more reliable and equally represent the ageing population in the study and understanding of the impact and implication of government policy template on health and ageing population.

Among other classes of the aged such as the unemployed, artisans, religious clergies, etc., the retirees of the federal institutions across the country are often affected by the health policy of the nation either positively or negatively as a 
result of long time attachment to the system and difficulty in withdrawal after retirement.

The major thrust of this paper in line with the above issues raised is to unveil and examine the extent of access to public health facilities by the retirees of the federal institutions in the southeast Nigeria, their satisfaction with the services in comparison to the health policy template of the federal republic of Nigeria and the factors determining the likelihood of regular medical checkups and health maintenance. In line with the above introduction, the present work is interested in answering the following questions

i. How are the retirees of the federal government institutions in the south east Nigeria managing their health since their retirement in view of the extant federal government public health policy?

ii. Are there specific health packages via public health policy for the aged in managing their health outside the general population?

iii. What are the determining factors to regular health upkeep among the retirees of the federal government institutions in the south east Nigeria?

iv. What are the determining factors to satisfactory health services to the retirees of the federal government institutions in the south east Nigeria?

\section{Review of Relevant Literatures}

\subsection{Ageing, a Current and Future Reality in sub-Saharan Africa and Nigeria in Particular}

As a natural order than human-induced, ageing is an indisputable fact after the conception has taken place. According to Kirkwood (2008), there is complexity in the ageing process and the factors influencing it. In physiological life studies, ageing has been observed to involve a large extent of molecular and cellular degradation (Steves, Spector, \& Jackson, 2012; Vasto, et al., 2010). With time, the accumulated damage to the molecular and cellular components degenerate into an increase in vulnerability to morbidity and eventually to death (Ritu, et al, 2015). Invariably, human beings no matter their wealth, social status and efforts to remain relatively young will certainly come to the point of degeneration requiring, the assistance of others from microcosm (individual relatives) to macrocosm (the society at large).

For epistemological interest and social consumption of knowledge, social demography has put in perspective, the realities of the stages of life in the society following the fundamental knowledge of cellular regeneration and degeneration (Kirkwood, 2008). In respect to the stages of life in the society, human beings grow from the level of dependency (childhood dependency) through the stage of active responsibility (being depended on) to another stage of dependency (old-age dependency) (Blakes, 1956). This situation, as observed by social demography and allied disciplines, becomes more pronounced with the change of life expectancy from death. Before now, such a situation was more of domestic affairs than public affairs as it appears currently across the globe, owing to the traditional nature of the majority of the global nations before industrialization. However, in the post-industrialization era when an improvement in health, science and technology is the order of the day, the realities of the changing stages of life in the society especially, regarding ageing have increasingly become one of the social policy issues across the globe.

While in sociodemographic realities, the societies now feel the presence of helpless members of the society with degenerating health and socioeconomic conditions, in biostatistical and spatial analysis, the number of the members of the society with the aforementioned conditions has been projected to continue on the steady increase across the globe.

According to Velkoff and Kowal (2006), about $63 \%$ of the global ageing population currently can be found in developing nations such as sub-Saharan Africa. This is expected to increase by $10 \%$ in the coming 25 years. According to a breakdown by the United States of America Bureau of Population (2005), by 2030, more than 30 per cent of the population of Europe is expected to fall in the category of ageing population (60 years and above). Similarly, in Asia, Latin America and the Caribbean, the ageing population is likely to double before the coming 25 years. In sub-Saharan Africa, the ageing population (60 and over) are likely to grow to 5.5 per cent in 2030.

According to statistical publication in 2005 by the U.S census bureau, Nigeria was located at the 30th position on the calendar charts of the nations across the globe, with the larger population of the aged 60 and above. Six additional sub-Saharan African countries such as Ethiopia, Ghana, Kenya, Tanzania, Sudan and Congo (Kinshasa) recorded above one million people aged 60 and above in 2005 (Velkoff \& Kowal, 2006).

Although population ageing may appear to be less relevant to sub-Saharan Africa compared to the Europe, North 
America and some Asian nations presently, the implication of emerging demographic changing of ageing in the population structure still have overwhelming domestic policy issues (Ulrike, et al., 2015).

From the foregoing, the certainty of continuous growth of the ageing population in sub-Saharan Africa remains indisputable. However, beyond the biostatistical analysis of ageing population in sub-Saharan Africa, there are other sociodemographic factors solidly behind the current nature of population ageing in sub-Saharan Africa and, these sociodemographic factors will continue to influence the future growth of the population ageing. According to Ulrike et al (2015), two key factors that have affected ageing across the globe included the increased life expectancy at age 60 powered, by unprecedented socioeconomic development in the past 50 years. Secondly, the falling fertility rates across the globe, especially among the developed and developing nations such as in sub-Saharan Africa, has affected maternal mortality rates. Of course, maternal mortality rates, especially in sub-Saharan Africa, are one of the strong force that influenced mortality trajectory and by implication, life expectancy among the female members of the population. In addition to the observation by Ulrike et al, (2015), other sociodemographic factors such as the "proxy policy compulsion" by the United Nations allied bodies. In pursuit of the millennium development goals, which is the indices for measuring development and commitment by the member nations, nations across the globe, especially in sub-Saharan African region have set out developmental policies, which in their utilitarian values have triggered improved quality of life. The by-products of most of these policies and activities end up as improved life expectancy among the members of the population.

Nigeria as one of the sub-Saharan African nations and a member of the United Nations body is not an exception in the analysis of the factors influencing life expectancy and the realities of ageing in the present and future time projection. Nigeria has in principle, subscribed to the proxy humanitarian and developmental policies that by their nature is expected to fuel the increase in life expectancy in the coming years.

\subsection{The Plight (Health) of the Aged in Nigeria and the Web of Contributing Factors}

The plights of the aged world over cannot be overemphasized in view of their vulnerable situation in the family, community and nation. Although comparative analyses of the wealth of the nations have delineated the world into developed and developing nations, the issue of the plights of the aged cut across all walks of life. However, there are differences, which hinges on the evidence of absolute and relative poverty. Generally, the aged face some challenges such as degenerating health conditions (Prince, Bernabei, Chan, Gutierrez-Robledo, Jean-Pierre, Morley, Ong, Leocadio Rodriguez Manas, Alan Sinclair, Won \& Vellas, 2015; Staudinger, Finkelstein, Calvo \& Sivaramakrishnan, 2015; Foebel \& Pedersen, 2015), abuse (Pillemer, Burnes, Riffin \& Lachs, 2015; WHO, 2002; Mudiare, 2013), financial handicap (Fried, 2016; Ong, 2016; Kim \& Fritsch, 2016), isolation (Bezerra, 2016; Costa, Kalache, \& Voelcker, 2015), etc. All these challenges and more put together boils down to the health of the aged.

While degenerating health condition practically subdues the aged to physical weaknesses and some level of vulnerabilities, abuse of the elders, compounds both their emotional health and where the abuse involved some level of violence, it complicates their physical health. Similarly, financial handicap causes the aged to become vulnerable to inadequate health care especially, in places where user fee policy is in the direction of self-sponsorship. Isolation also, as one of the challenges of the aged, can result in emotional as well as physical health complications.

Beyond the general and perhaps, common challenges of the elderly across the globe, there are more vulnerable situations, which the aged face in the developing nations especially, among the sub-Saharan African nations. The peculiarities of these vulnerabilities lie in their nature and causes. For instance, these challenges, by their nature and causes, are not easily found among the developed nations due to individuals, government and Nongovernmental Organizations' approaches in mitigating such challenges even before they surfaced. Among other things, these, include violence/conflict, neglect, physical/emotional isolation, technical exclusion by the government, abuse of the elders, used and dump, etc.

Violence and conflict have become the evidence of political, religious and ethnic fallout among the sub-Saharan African nations (Bramucci \& Erb, 2007). Apart from children and women, the elderly are the third square of the triangle of effect. In the emotional aspect of it, the elderly are more affected compared to other vulnerable groups. While the youth may easily adapt in the time of displacement during the time of conflict, the children know nothing and simply follow the parents or whoever that may be available to take them out of the conflict zone. However, the elderly become emotionally suppressed looking at their ancestral land being abandoned to the unknown. Also, adapting to the new location becomes more difficult for them both on the issue of their health conditions and the time lag for familiarization with new terrain. Situations in South Sudan, Central African Republic, Cameroun, DR Congo, Nigeria and Somalia, depicts both the height of human-induced pains for the elders and their vulnerability to ineffective government. 
The elders in the sub-Saharan African nations often face the problem of neglect by their families, communities and even government. This can be visible mostly during the time of deteriorating health conditions, which often mark the period of ageing (Hosegood \& Timaeus, 2006; Kahn, Tollman, Thorogood, Connor, Garenne, Collinson, \& Hundt, 2016). In some cases, as recorded in Nigeria and Ghana, the elderly are simply classified as witchcraft when certain behavioural changes as a result of age set in (Ogunniyi \& Aboderin, 2007; van der geest, 2007; Uwakwe \& Modebe, 2007). In the process of classifying them as witchcraft or viewing the health challenges as spiritually connected, they are neglected and sometimes totally abandoned by their family members, communities and of course government that does not regard them as assets compared to the youth and the children.

Every human being at all levels needed emotional and physical companionship to lighten their lives (Rituetal, 2016; Bramucci \& Erb, 2007, WHO, 2002; Garcon, 2016). This can be visible observing the difference in the appearances of the elderly with consistent companionship at home and in the community, and the elderly people from broken families and isolated or self-isolated elders (Bramucci \& Erb, 2007). In sub-Saharan African nations, emotional and physical companionship have more to do with social status than the dignity of man and this, runs from the family to the entire society (Lam, Leibbrandt, \& Ranchhod, 2007). Due to the dominant capitalistic tendencies in most of these nations, relationship and companionship run on the strand of materialistic values. In essence, this becomes the problem of the aged as soon as their productivity capacity began to wind down. This becomes more complex when they leave public offices and responsibilities into private lives, which usually force them into isolation.

Despite the empirical validation of demographic shift in sub-Saharan Africa (Velkoff \& Kowal, 2007; U.S Bureau of Population, 2005; United Nations, 2016; United Nations Department of Economic and Social Affairs, 2016), the Political Declaration and Madrid international plan of action on ageing (United Nation, 2002), and the World HealthOrganization's Active ageing (International Covenant on Economic, Social and Cultural Rights, 1966; WHO, 2002; Beard \& Ferguson, 2016); most sub-Saharan African nations, especially Nigeria are yet to technically reflect the peculiar conditions of the aged in the major thrusts of their social policies. Where the issues affecting the aged specifically appeared in the social policies, they appear as an appendage, making it more or less, vulnerable to an omission by the policy implementers.

Although abuse of the elders appeared to be global (Pillemer, Burnes, Riffin, \& Lachs, 2016, WHO, 2002), the manner in which it manifests in sub-Saharan Africa makes it more threatening than in the developed nations. While in the developed nation's abuse of the elders take the form of emotional abuse and in rare cases, physical abuse (Moreno \& Imamura, 2016; Pillemer, Burnes, Riffin, \& Lachs, 2016; Dannefer, 2003; Nash, 2016). However, in the sub-Saharan African region, the incidence of abusing of the aged takes a different dimension. Indices to prove government reluctant attitude to the matters concerning the aged includes the manner in which certain cases of abuse of the aged can be treated.

In Ghana, for instance, the incidence of threatening the elderly because of complaining about their problems have automatically made the elders sink into self-denigration (Van der geest, 2007). Among the aged in some urban settings in Kenya, abuse of the elderly get to the point of regular physical violence by the members of their household without any hope of genuine intervention from outsiders at least, for help and emotional healing (Ezeh, Chepngeno, Kasiira, \& Woubalem, 2007).

In the Darfur region, reports have emerged of the reckless abuse of the elders by both the youths and adult members of their families and communities. According to Bramucci and Erb (2007), even in the Internally Displaced Camp, some adults and families use the aged in the camp to increase the number of their household for large quantity of portion from the charity organizations running the camps but latter abandon these helpless fellows without any benefit or even ordinary physical assistance they needed for their survival in the IDP camp.

In Nigeria, situations have emerged where the elderly women were raped in mass by young men in a night without a single intervention from any security agency or even their neighbours (Ani, 2012 as cited in Medicare, 2013). Similarly, the elderly fellows in some parts of Nigeria have submitted that both their values and the duty of the society towards them are dying away as days go by (Mudiare, 2013; Akpan \& Umobong, 2013). Cases have emerged in Nigeria also, where the elderly have been abandoned in the psychiatric hospitals by their family members due to lack of money and in some cases, witchcraft accusations; a case that has also appeared in Ghana (Ogunniyi \& Abodering, 2007; Uwakwe \& Modebe, 2007; Van de geest, 2007).

Domestic violence, inter/intra tribal/ethnic and political violence in Nigeria, finally collapse on the head of the aged and aggravate their emotional and health complications. While the aged can be neglected because of economic difficulties, careless attitude by the people around them and family priority, they can be deliberately isolated by the members of their families for reasons ranging from discomfort from their health condition, witchcraft accusation, to 
intra family conflict and misunderstanding.

Technical exclusion of the aged by the government in the social policy structure is the zenith of their plight in Nigeria, with a greater impact on their health. Technical exclusion appears in the form of ignoring the aged in the social policy structure by lumping them with every other member of the society except the infants and the pregnant women. Yet, these are people with special needs as the children and pregnant women, who cannot help themselves. Similarly, there is no standard policy controlling the fate of the aged retiring from the private sector thus, making them vulnerable to the heartless profit-mad private organizations. All these boil down to the health of the aged in Nigeria, who in most cases cannot help themselves from any other source. Of course, someone, who has no regular means of income and assistance after retirement from his job simply become a feast to degrading health condition till death closes the case.

\subsection{National Health Policies in Nigeria [1988-2016] and the Evidence of Exclusion of the Ageing Population}

Public policy as a legal framework is a tool to capture the ongoing situations in the society, to give them conceptual structure, and to determine the position of the government in controlling the situations in the interest of the members of the society. Health is one of the ancient phenomenon, that has outlived generations and therefore, continue to hold sway on the members of the society, from the private stage (individual consciousness of health issues backed up by individuals' carefulness on managing their health), to the public stage (group consciousness of health issues backed up by government decisions on health to manage public health issues).

In the interest of the present work, health policy as part of public policies in Nigeria tolled the line of the public health concern across the globe in principle, which has necessitated the countries of the world to pursue strategies formalized as policy framework to meet the ever growing health needs of the national and global populations. This, in most cases has been initiated by the global body (the World Health Organization), while in other cases, it has been the outcome of scientific breakthrough and empirical evaluations of present and past health issues in different nations of the globe.

Nigeria health policy was first set up in 1988 with focus on the strategy to achieving health for all Nigerians (FMH, 2004; 2016). Although in principle the employees and experts in the sector set out for comprehensive review of the policy structure and major thrust between 1996 and 97, such move was stamped out by the then military regime of late General Sani Abacha. This was done by the refusal of the administration to endorse the revised policy. By 2003, the Department for International Development (DFID), under "The Health Sector Reform Change Agents, products of the Change Agent Programme (CAP)" forwarded a proposal in collaboration with the Nigeria Federal Ministry of Health to revisit the revised health policy with further review of the policy based on the experience and observations of the Department For International Development in other developing nations (FMH, 2004). The proposal by the DFID was considered perhaps due to their offer to sponsor the program and the civilian government of Mr. Olusegun Obasanjo, which had human face to public concerns compared to the military regime. This collaboration with the DFID gave birth to the first revised health policy in Nigeria. By 2014, there was first national act, which in principle was in passivity towards the Millennium Development Goals by the United Nations (FMH, 2016). The new national health act of 2014 and perhaps, the first legal justification of public health policy in Nigeria, resulted in the series of consultations that yielded to the second revised health policy of 2016 and perhaps, the most currently health policy standard in Nigeria.

While the health sector has relatively gained proper access into the national assembly and by implication is licensed to make demands in view of the ever growing public health needs, much is left to be desired for. For instance, the current health policy lacks popularity and utilitarian values to the majority of the masses. While the policy limited decision to public health issues especially, funding and location of health facilities to the federal structure, under a three tier government structure, the state and local governments are answerable to decisions from the federal ministry of health a situation, which dampens the diversification of the policy thrusts to accommodate emerging issuesin time (NDHS, 2013).Furthermore, the pseudo technical structures set up for monitoring and evaluation across the nation are simply for formality purposes (see Federal Ministry of Health, 2016: 24).

Of course, this has resulted in the location of certain health facilities away from majority of those who needed those most. This condition, mostly affected the aged, who cannot easily access certain health facilities due to their locations especially in the rural settings where most of this category of people are residing.

The public health policy in Nigeria, acknowledge in principle but not in practice, the imperative of specialty in the handling of medical cases among the medical practitioners (Nigeria Health systems assessment 2008) a condition, that is more disastrous than lack of health facilities. In most of the health facilities across the nation especially, in the 
rural areas, one medical doctor sits down from year to year handling multiple cases, most of them in trial and error. According to Federal Ministry of Health, "The availability of health facilities does not translate into the availability of quality healthcare services. Certain services are not generally available to a large percentage of the population" (P.14). This has even created a niche for the private health facilities to operate as jack of all trade. This condition is one of the deadly situations the elderly people, especially the poor are facing in Nigeria. In some cases, the aged are brought to some of these health facilities to die in instalment in health conditions, which required a simple and precise approach to resolve.

The Nigerian public health policy has made the public and private health facilities cash and carry (i.e. user fee policy). While in principle, certain healthcare services by the public health facilities are meant to be free, the health workers especially in the rural settings invent some means of extortion to even collect more than what the service users would have paid in the private health facilities. The most affected in this situation, is the aged in the general population. By 2016, the federal ministry of health reported that less than 5 percent of the population is on any form of health insurance scheme. While this represent a scratch of the entire population currently in the nation, retirement procedures and benefits in the country has no space for health insurance of the retired, making it clear that the retirees are simply out of any form of healthcare assistance plan. The aged have no specific recognition in view of both their peculiar health conditions and financial handicap. In reality, majority of the aged are financially handicapped and cannot afford to seek for healthcare services under the current situation. This, has led most of them to rely heavily on over-the counter drugs and self-medication.

In categorical public health policy objective statements, the Nigerian public health policy acknowledged the Reproductive, Maternal, Neonatal, Child and Adolescent Health of which the aged in their extent of vulnerabilities and peculiarities were totally ignored. In the policy objective specificity, the policy objective maintained that the thrust of the public health policy in Nigeria will focus on infant and maternal, with little interest on the general public (see Nigerian public health policy, 2016:28).

Although the inclusion of the adolescence can be canvassed for as the inclusion of the elderly, this is still ambiguous in the face of ever growing challenges of the elderly in terms of morbidity and financial requirements. The implication of the structure of the objective of the public health policy in Nigeria can be understood more by looking at the way such objectives have shaped the healthcare services in Nigeria. Due to the attention given to the infant and maternal issues in the public health policy, there is a relative difference in the way these categories of people are approached in the publichealth facilities. This has even spilled over to the private health facilities such that, wherever any health facility is located in Nigeria, the two categories of people are seen as the people with special need.

The elders are simply in the same special condition with the pregnant women and the infants. They can be fragile and their health condition always go with some level of emergency however, is only the problem of where the people recommending for the government, focuses their attention in terms of classifying the members of the society and health conditions. The elderly cannot struggle with the other members of the society in accessing public health facilities or wait all day long with their fragile health. However, this is the situation in Nigeria especially in the rural setting, where more of the poor ageing population resides. In some cases, their health conditions have been over looked and given blanket treatment with that of other people in the same hospital setting either because of their financial handicap or the attitude of the health workers in the facility.

According to the policy orientation/initiative for mental health in Nigeria, the policy is focused to mitigate the common mental issues order than the specialized mental health issues affecting the elderly persons, mostly because of the age and deteriorating health conditions (see Nigerian public health policy, 2016:36-37).

With a close look at this policy statement, the special cases peculiar to the elderly such dementia and Alzheimer were technical out of place. Even though the policy statement in it crude form included the adults in the Nigerian society, situations have emerged where the elderly persons were partially excluded in some of the Nigerian psychiatric hospital on the assumption that they are mostly likely to be suffering from witchcraft and spiritually related problems hence the recommendation of spiritual healers (Uwakwe \& Modebe, 2007).In the cases of dementia, Nigerian health facilities lacks professionals and specific facilities for the problem and even does not give attention to such, owing to the unavailability of diagnosing equipment for the disease. The rare facilities for this disease can be found in only two places in Nigeria such as in university of Ibadan (Ogunniyi \& Aboderin, 2007) and the extension of the NnamdiAzikiwe Teaching Hospital (courtesy of few individual concerned from the hospital and collaboration with concerned international organization) (Uwakwe \& Modebe, 2007). The two locations are operated on private basis and they are still at infantry stage. In the case of Alzheimer, there is yet to be attention towards such in Nigeria even among the private health merchants who become the succour when the public facilities failed. The most important of 
this situation with the current and past public health policy structure, is that there are hidden ageing population who are down with most of these health challenges peculiar to the aged.

\section{Methodology}

The study specifically captured the retirees of the federal government institutions in the southeast region of Nigeria. The study utilized the retiree population to represent the ageing population in the region although this is not a perfect representation. There are about 10 year's intervals in our inclusion criteria of the retirees. The suitability and relevance of the retirees of the federal institutions in the region for this type of study is in connection with the consistent age documentation, which helped the study overcome the hurdle of age classification among the general population.

While it is obvious that the accurate documentation and tracing of the retired federal institution workers can be difficult, the study adopted snowball technique and referral strategies in locating these retirees in the nearby cities and communities.

The study was carried out among the 5 states in southeastern Nigeria with a focus on the major cities that have the presence of federal institutions such as federal educational institutions as well as federal government parastatals. On average, two cities were selected from each of the five southeast states with such inclusive criteria as the location of federal institutions and proximity to the host communities.

The study adopted a cross-sectional survey design in view of the issues raised in the study. The study adopted modified random sampling techniques in selecting the respondents. Modified random sampling was adopted in selecting the respondents (using the available documentation at the selected institutions bearing a link to the permanent address of the retirees). However, where the researchers faced the problems of improper documentation and missing link between the demented address and the current residency, snowball and referral strategies were applied to include more respondents towards achieving the proposed sample size of the study. In total, fifteen cities and communities were selected for the study. In each of the 15 cities and communities selected for the federal institutions, 40 retirees were selected using modified simple random sampling, bringing together, 600 respondents for the study.

The instrument for the study was a survey questionnaire developed on a nominal scale with a specific focus on the indices of public health policy in Nigeria and the health needs of the ageing population under study. The questionnaires were self-administered with some guidance from the researcher where the respondents requested for assistance. The researchers targeted the days the personnel units of the selected institutions addresses the retirees, for the sharing of the questionnaires. The data collected were coded and analyzed using Social Science Statistical Package (SPSS version23) while the research questions guiding the study were answered/tested with descriptive and inferential statistics such as percentages and logic Regression

\section{Presentation of Findings}

The table 1 presented the description of access to health services and health upkeep of the retirees of the federal institutions in the south east Nigeria according to design of this study. From the table, majority of the retirees (77.3\%) do not maintain standard regular medical checkups and treatment. Out of the 600 retirees surveyed, only 35.5\% receive support from their relatives for medical upkeep. More than $80 \%$ of the retirees surveyed are not satisfied with the quality of the services rendered at the public health facilities while only $10.2 \%$ attested to have observed or used special health facilities for the aged. From the survey, only five percent of the retirees indicated to have accessed any form of health package from the federal government to the aged. More than $80 \%$ of the retirees surveyed manage their health by self support while only $18 \%$ have managed their health through government subsidized health services during their active service days. Meanwhile only 9.3 percent of the retirees indicated to have enrolled for any form of government health insurance scheme during their active days in service. More than $50 \%$ of the retirees surveyed indicated that they live about 5 kilometres and more from any visible government health facility while more than $60 \%$ indicated that they live in the rural areas. 
Table 1. Summary of the Descriptive Statistics

\begin{tabular}{|c|c|c|c|}
\hline \multicolumn{2}{|c|}{ Summary of the descriptive statistics } & \multirow{2}{*}{$\frac{\mathrm{N}}{309}$} & \multirow{2}{*}{$\begin{array}{c}\text { Percentage } \% \\
51.5 \%\end{array}$} \\
\hline Gender & Males & & \\
\hline & Females & 291 & $48.5 \%$ \\
\hline \multirow[t]{5}{*}{ Educational qualifications } & Primary education & 6 & $1.0 \%$ \\
\hline & Secondary school & 76 & $12.7 \%$ \\
\hline & NCE/Diploma certificate & 175 & $29.2 \%$ \\
\hline & first Degree certificate & 207 & $34.5 \%$ \\
\hline & M.Sc/PhD certificate & 136 & $22.7 \%$ \\
\hline \multirow[t]{4}{*}{ Period of retirement } & Less than last one year & 98 & $16.3 \%$ \\
\hline & Last $1-2$ years & 86 & $14.3 \%$ \\
\hline & Last 3-4 years & 268 & $44.7 \%$ \\
\hline & Last 5-more years & 148 & $24.7 \%$ \\
\hline \multirow[t]{2}{*}{ Place of residence after retirement } & Urban & 216 & $36.0 \%$ \\
\hline & Rural & 384 & $64.0 \%$ \\
\hline \multirow[t]{4}{*}{ Distance from government hospital } & Less than 1 kilometre & 61 & $10.2 \%$ \\
\hline & 1-2 kilometre & 102 & $17.0 \%$ \\
\hline & 3-4 kilometre & 111 & $18.5 \%$ \\
\hline & 5 kilometre and more & 326 & $54.3 \%$ \\
\hline Involvement in federal government health & Yes & 195 & $32.5 \%$ \\
\hline insurance scheme during active service & No & 405 & $67.5 \%$ \\
\hline Involvement in federal government health & Yes & 56 & $9.3 \%$ \\
\hline insurance scheme after retirement & No & 544 & $90.7 \%$ \\
\hline How they manage their health during active & Self-support & 492 & $82.0 \%$ \\
\hline service & Government subsidized health services & 108 & $18.0 \%$ \\
\hline \multirow[t]{2}{*}{ How they manage their health after retirement } & Self-support & 531 & $88.5 \%$ \\
\hline & Government subsidized health services & 69 & $11.5 \%$ \\
\hline Awareness of federal government health & Yes & 41 & $6.8 \%$ \\
\hline packages for the aged & No & 559 & $93.2 \%$ \\
\hline Accessing any federal government health & Yes & 30 & $5.0 \%$ \\
\hline packages for the aged & No & 570 & $95.0 \%$ \\
\hline Observing and using special health facility for & Yes & 61 & $10.2 \%$ \\
\hline the aged in government hospital & No & 539 & $89.8 \%$ \\
\hline Feeling satisfied with health services at & Yes & 108 & $18.0 \%$ \\
\hline government hospitals & No & 492 & $82.0 \%$ \\
\hline Receiving support from relatives for medical & Yes & 213 & $35.5 \%$ \\
\hline upkeep & No & 387 & $64.5 \%$ \\
\hline Going for regular medical checkup and & Yes & 136 & $22.7 \%$ \\
\hline treatment & No & 464 & $77.3 \%$ \\
\hline Total & & 600 & $100.0 \%$ \\
\hline
\end{tabular}

Field Survey, 201 
Table 2. Logistic Regression on Satisfaction with the Health Services at Government Health Facilities and Other Variables

\begin{tabular}{|c|c|c|c|c|c|c|}
\hline & $\mathrm{B}$ & S.E. & Wald & Df & Sig. & $\operatorname{Exp}(B)$ \\
\hline Step $1^{\text {a }}$ Receiving support & -1.971 & .265 & 55.171 & 1 & .000 & .139 \\
\hline Education & -.321 & .176 & 3.314 & 1 & .019 & .725 \\
\hline Period of retirement & -.049 & .107 & .208 & 1 & .648 & .952 \\
\hline Distance from public health facilities & 1.101 & .145 & 57.535 & 1 & .000 & .333 \\
\hline $\begin{array}{l}\text { Using special facility for the aged at the public } \\
\text { health facilities }\end{array}$ & 1.179 & .256 & 21.236 & 1 & .000 & 3.252 \\
\hline $\begin{array}{l}\text { Awareness of government public health } \\
\text { policies }\end{array}$ & .311 & .262 & 1.409 & 1 & .235 & 1.364 \\
\hline $\begin{array}{l}\text { Means of managing their health before } \\
\text { retirement }\end{array}$ & -.296 & .258 & 1.309 & 1 & .025 & .744 \\
\hline Means of managing their health after retirement & $\mathrm{tt}-.572$ & .300 & 3.648 & 1 & .026 & .564 \\
\hline $\begin{array}{l}\text { Involvement in Health insurance scheme during } \\
\text { active service }\end{array}$ & $g_{3.362}$ & .855 & 15.468 & 1 & 1.000 & 28.857 \\
\hline Place of Residence (urban or rural) & -1.217 & 24020.036 & 13.011 & 1 & .000 & 1.000 \\
\hline Sex & -19.492 & 5628.140 & 8.074 & 1 & .997 & .000 \\
\hline Constant & 63.609 & 45743.616 & 15.684 & 1 & .000 & 42.184 \\
\hline
\end{tabular}

Dependent variable: Satisfaction with the health services at government health facilities.

Field Survey, 2019

Overall Percentage classified $=95.3 \%$; Goodness of fit test $=.0005 ; \chi^{2}$ Value $=485.654(\mathrm{df14})$; Cox \& Snell $\mathrm{R}^{2}=$ $55.5 \%$; Nagelkerke $\mathrm{R}^{2}=84.4 \%$

Note: Result is significant at $.05(\mathrm{p}<.05)$

The above table 2 presented the binary logistic regression on satisfaction with the health services at government health facilities and other variables. The collected data were coded to follow the binary logistic regression default, while the data were test-ran to avoid outliers. The overall strength of the model in explaining satisfaction with the health services at government health facilities to the aged, according to the pseudo $\mathrm{R}^{2}$ (Cox \& Snell $\mathrm{R}^{2}$ and Nagelkerke $\mathrm{R}^{2}$ ) is between $55.5 \%$ and $84.4 \%$. Among the variables of interest, receiving support from relations, education, distance from public health facilities, using special facilities means of managing their health before and after retirement and place of residence significantly contributed to the explanation of being satisfied with health services at public hospitals among the aged. However, some of the factors contributed in the negative direction according to the regression model. These factors included, receiving support from the relations, education, Means of managing their health before and after their retirement and their place of residence.

The table 3 presented the binary logistic regression on satisfaction with the health services at government health facilities and other variables. The collected data were coded to follow the binary logistic regression default, while the data were test-ran to avoid outliers. The overall strength of the model in explaining satisfaction with the health services at government health facilities to the aged, according to the pseudo $\mathrm{R}^{2}$ (Cox \& Snell $\mathrm{R}^{2}$ and Nagelkerke $\mathrm{R}^{2}$ ) is between $44.9 \%$ and $73.5 \%$. Among the variables of interest, receiving support from relations, level of education, distance from public health facilities, means of managing their health before and after retirement, involvement in health insurance scheme during active service and place of residence significantly contributed to the explanation of being satisfied with health services at public hospitals among the aged. However, some of the factors contributed in the negative direction according to the regression model. These factors included, distance from public health facilities, means of managing their health before and after retirement, Means of managing their health before and after their retirement and Involvement in Health insurance scheme during active service. 
Table 3. Logistic Regression on Regular Medical Checkup/Health Maintenance and Other Variables

\begin{tabular}{|c|c|c|c|c|c|c|c|}
\hline & & $\mathrm{B}$ & S.E. & Wald & Df & Sig. & $\operatorname{Exp}(B)$ \\
\hline \multirow{12}{*}{$\begin{array}{l}\text { Step } \\
1^{\mathrm{a}}\end{array}$} & Receiving support & 1.348 & .228 & 35.108 & 1 & .000 & .260 \\
\hline & Level of education & 640 & .170 & 14.179 & 1 & .000 & .527 \\
\hline & Period of retirement & .217 & .097 & 5.000 & 1 & .055 & 1.242 \\
\hline & Distance from public health facilities & -.235 & .124 & 3.592 & 1 & .028 & .791 \\
\hline & $\begin{array}{l}\text { Using special facility for the aged in } \\
\text { public health facilities }\end{array}$ & .135 & .091 & 2.201 & 1 & .138 & 1.144 \\
\hline & $\begin{array}{l}\text { Awareness of government public health } \\
\text { policies }\end{array}$ & -.275 & .241 & 1.303 & 1 & .254 & .760 \\
\hline & $\begin{array}{l}\text { Means of Managing their health before } \\
\text { retirement }\end{array}$ & -.536 & .226 & 5.613 & 1 & .018 & .585 \\
\hline & $\begin{array}{l}\text { Means of Managing their health after } \\
\text { retirement }\end{array}$ & -.818 & .238 & 11.760 & 1 & .001 & .441 \\
\hline & $\begin{array}{l}\text { Involvement in Health insurance } \\
\text { scheme during active service }\end{array}$ & -.931 & .270 & 11.904 & 1 & .001 & .394 \\
\hline & Place of Residence (urban or rural) & 6.160 & .892 & 47.717 & 1 & .000 & 473.440 \\
\hline & Sex & .000 & 64.301 & .000 & 1 & 1.000 & 1.000 \\
\hline & Constant & 2.552 & 2.206 & 2.0917 & 1 & .000 & 27.661 \\
\hline
\end{tabular}

Dependent variable: Regular medical checkup and health maintenance

Field Survey, 2019

Overall Percentage classified $=90.8 \%$; Goodness of fit test $=.0005 ; \chi^{2}$ Value $=357.257(\mathrm{df13})$; Cox \& Snell $\mathrm{R}^{2}=$ $44.9 \%$; Nagelkerke $\mathrm{R}^{2}=73.5 \%$

Note: Result is significant at $.05(\mathrm{p}<.05)$.

\section{Discussion and Conclusion}

Ageing among the sub-Saharan African nations appeared to be an emerging issue requiring a pragmatic policy approach from the government and the Nongovernmental organizations interested in the phenomenon. Among other things, health issues among the ageing population require a pragmatic policy approach to mitigate the likelihood of crises among this population category. However, while the aforementioned situation is necessary and calls for urgent attention, the situation on the ground projects a totally different scenario in Nigeria.

From the findings of the study, there is virtually no niche in the public health policy in Nigeria acknowledging the peculiarity of the ageing population. For example, only 6.8 percent of the 600 retirees of the federal institutions in southeast Nigeria indicated to have received any form of health subsidies said to be connected to the federal government of Nigeria. In reality, there is, according to the public health policy in Nigeria (1988-2016), no health insurance scheme outside the civil service commission accommodating the common citizens let alone the ageing population. Equally, majority of the retirees (82\%) who were surveyed in this study indicated lack of satisfaction with health services provided at the public health facilities and this correlated according to the regression model with their level of education before retirement, support from their family members, distance from government health facilities, place of residence, etc. While the level of education here appeared in the negative direction according to the beta (B) value, it points to the ability of the aged to discern the quality of the services provided in the public health facilities especially as it affects the ageing population with peculiar health needs. Also, receiving support from the family members for medical upkeeps encourages the aged to seek better medical attention at the private hospitals, which gives room for comparison of the government and private health facilities.

One of the hallmarks of the ageing process is the degeneration of the human body cells (morbidity). To meet with such a situation as inalienable, there is a need for regular health checkups and maintenance among the affected segment of the population. In reality, according to the findings in the current study, only about $20 \%$ of the retirees 
here surveyed go for regular medical checkups while more than $70 \%$ indicated that they do not go for regular medical checkups. In essence, this is pointing to the fact that most of these retirees either wallow up with their health complications or relied on self-medication in making up with their health challenges. The regular health maintenance here negatively correlated in the model with distance from the public health facilities, means of managing their health before retirement, means of managing their health after retirement and involvement in health insurance scheme during active service pointing, to the socio-economic implication of retirement to regular health maintenance.

The emerging issues of ageing cannot be overemphasized as this is evidence in the demographic outlook of the sub-Saharan African nations of which Nigeria is one of them. Although the current study could not capture absolutely the ageing population in southeast Nigeria let alone Nigeria, the study was determined to scratch the complex situation, which already exists with us in sub-Saharan Africa. Specifically, the study has unveiled the tip of the iceberg over the ageing population and their challenges, which are structurally embedded in the public health policy formulation and implementation in Nigeria.

\section{References}

Aboderin, I. (2007). Development and Ageing Policy in Sub-Saharan Africa: Approaches for Research and Advocacy. International Federation on Ageing: Global Ageing: Issues \& Action, 4(3), 7-22.

Aboderin, I. A., \& Beard, J. R. (2015). Older people's health in sub-Saharan Africa. Lancet, 385(9968), 9-11. https://doi.org/10.1016/S0140-6736(14)61602-0 PMID: 25468150

Adebowale, S. A., Atte, O., \& Ayeni, O. (2012). Elderly Well-being in a Rural Community in North Central Nigeria, sub-Saharan Africa. Public Health Research, 2(4), 92-101. https://doi.org/10.5923/j.phr.20120204.05

Akpan, I. D., \& Umobong, M. (2013). An Assessment of the Prevalence of Elder Abuse and Neglect in Akwalbom State, Nigeria. Developing Countries Studies Online, 3(5), 10-15.

Ani, S. (2012). Village where youth rape widows: suspects regain freedom free hours after arrest. Sunday Sun Newspaper, March 18, 6(467), 8-10.

Augusto, E., \& Bezerra, D. (2015). Integrating ageing into Brazil's national family health strategy. In World Health Organization (P.113), World Report on Ageing and Health. Geneva: World Health Organization Press.

Baerd, B., Bhushan, A., Taleb, H. A., Vasquez, J., \& Thomas, R. (2015). The right to health of older people. In World Health Organization: World Report on Ageing and Health. Geneva: World Health Organization Press.

Beard, J., \& Ferguson, L. (2015). International legal and policy frameworks on ageing. In World Health Organization (P.5): World Report on Ageing and Health. Geneva: World Health Organization Press.

Blume-Peytavi, U., Kottner, J., Sterry, W., Hodin, M. W., Griffiths, T. W., Watson, R. E. B., Hay, R. J., \& Griffiths, C. E. M. (2015). Age-associated skin conditions and diseases: current perspectives and future options. In World Health Organization: World report on ageing and health. Geneva: World Health Organization Press. https://doi.org/10.1093/geront/gnw003

Bramucci, G., \& Erb, S. (2007). An Invisible Population: Displaced Older People in West Darfur. International Federation on Ageing: Global Ageing: Issues \& Action, 4(3), 23-34.

Centers for Disease Control and Prevention. (2015). Healthy aging \& the built environment. In: Centers for Disease Control and Prevention [website]. Atlanta, GA: Centers for Disease Control and Prevention. Retrieved 17 June, 2015 from http://www.cdc.gov/healthyplaces/healthtopics/healthyaging.htm

Cesari, M., Prince, M., Bernabei, R., Chan, P., Gutierrez-Robledo, L. M., Michel, J. P., Morley, J. E., Ong, P., Manas, L. R., Sinclair, A., Won, C. W., \& Vellas, B. (2015). Frailty: an emerging public health priority. In World Health Organization: World Report on Ageing and Health. Geneva: World Health Organization Press. https://doi.org/10.1016/j.jamda.2015.12.016

Costa, S., Kalache, A., \& Voelcker, I. (2015). Individualized care plans for older people living in slum areas in Rio de Janeiro, Brazil. In World Health Organization (P.105): World Report on Ageing and Health. Geneva: World Health Organization Press.

Dahida, D. P., \& Maidoki, B. P. (2015). Public Policy Making and Implementation in Nigeria: Connecting the Nexus. Public Policy and Administration Research, 3(6), 56-64. 
Dannefer, D. (2003). Cumulative advantage/disadvantage and the life course: cross-fertilizing age and social science theory. J Gerontol B PsycholSciSoc Sci, 58(6), 327-37. https://doi.org/10.1093/geronb/58.6.S327

Davis, A., McMahon, C., Pichora-Fuller, K., Russ, S., Lin, F., Olusanya, B., Chadha, S., \& Tremblay, K. (2015). Ageing and hearing health. In World Health Organization: World report on ageing and health. Geneva: World Health Organization Press.

De Carvalho, I. A., Epping-Jordan, J., Pot, A. M., Kelley, E., Toro, N., Thiyagarajana, J. A., \& Beard, J. R. (2017). WHO Study on global AGEing and adult health (SAGE). In: World Health Organization, Health statistics and information systems [website]. Geneva: World Health Organization; 2015. Retrieved 23 January, 2019 from http://www.who.int/healthinfo/sage/en/

Ezeh A. C., Chepngeno. G., Kasiira A. Z., \& Woubalem, Z. (2006). The Situation of Older People in Poor Urban Settings: The Case of Nairobi, Kenya. In B. Cohen \& J. Menken (Eds.), Aging in sub-Saharan Africa: Recommendations for furthering research (pp. 189-213). Report of the National Research Council of the National Academies. Retrieved from http://books.nap.edu/catalog/11708.html

Federal Ministry of Health. (2016). National Health Policy: Promoting the Health of Nigerians to Accelerate Socio-economic Development. Abuja: Federal Ministry of Health.

Ferreira, M. (2005). Research on ageing in Africa: What do we have, not have and should we have? Generations Review, 15, 32-35.

Foebel, A. D., \& Pedersen, N. L. (2015). Genetic influences on functional capacities in ageing. In World Health Organization: World Report on Ageing and Health. Geneva: World Health Organization Press.

Fried, L. P. (2015). Investing in health to create a third demographic dividend. In World Health Organization: World Report on Ageing and Health. Geneva: World Health Organization Press.

Garcon, L. (2015). Financing long-term care in Japan. In World Health Organization (P.132). World Report on Ageing and Health. Geneva: World Health Organization Press.

Gina Bramucci and Susan Erb. (2007). An Invisible Population: Displaced Older People in West Darfur. In J. T. Sykes \& S. J. Aziz (Eds.), Global Ageing: Issues and Action, 23-34. International Federation on Ageing, 2007, 4(3).

Gureje, O., Lola, K., Ebenezer, A., \& Benjamin, O. O. (2008). Determinants of quality of life of elderly Nigerians: results from the Ibadan Study of Ageing. Afr J Med Med Sci, 37(3), 239.

Hosegood, V., \& Timaeus, I. M. (2006). HIV/AIDS and Older People in South Africa. In B. Cohen \& J. Menken (Eds.), Aging in sub-Saharan Africa: Recommendations for furthering research (pp. 250-275). Report of the National Research Council of the National Academies. In all cultures and societies. In M. L. Johnson (Ed.), The Cambridge handbook. Retrieved from http://books.nap.edu/catalog/11708.html

Joshi, H. E. (2006). The proliferation of birth cohort studies in the developed and developing world. Paper presented at the Workshop on Life course, Wellbeing and Public Policy in Developing Countries, 9-10 November, 2006, University of East Anglia, Norwich, UK.

Kahn, K., Tollman, S., Thorogood, M., Connor, M., Garenne, M., Collinson, M., \& Hundt, G. (2006). Older Adults and the Health Transition in Agincourt, Rural South Africa: New Understanding, Growing Complexity. In B. Cohen \& J. Menken (Eds.), Aging in sub-Saharan Africa: Recommendations for furthering research (pp. 166-188). Report of the National Research Council of the National Academies. Retrieved from http://books.nap.edu/catalog/11708.html

Kalache, A., Barreto, S. M., \& Keller, I. (2005). Global ageing: The demographic revolution in all cultures and societies. In M. L. Johnson (Ed.), The Cambridge handbook of age and ageing (pp. 30-46). Cambridge: Cambridge University Press. https://doi.org/10.1017/CBO9780511610714.005

Kaneda, T., Lee, M. A., \& Pollard, K. (2011). The well-being of older population across twelve countries: The comparative analysis based on the index on well-being in older populations. A paper presented at the population association of America 2011 annual meeting.

Kim, H. J., \& Fritsch P. (2015). Older people in humanitarian contexts: the impact of disaster on older people and the means of addressing their needs. In World Health Organization: World Report on Ageing and Health. Geneva: World Health Organization Press. 
Kirkwood, T. B. (2008). A systematic look at an old problem. Nature, 451(7179), 644-7. https://doi.org/10.1038/451644a

Lam, D., Leibbrandt, M., \& Ranchhod, V. (2006). Labor Force Withdrawal of the Elderly in South Africa. In B. Cohen \& J. Menken (Eds.), Aging in sub-Saharan Africa: Recommendations for furthering research (pp. 214-249). Report of the National Research Council of the National Academies. Retrieved from http://books.nap.edu/catalog/11708.html

Lee, H. S., \& Wolf, D. A. (2014). An evaluation of recent old-age policy innovations in South Korea. Res Aging, 36(6), 707-730. https://doi.org/10.1177/0164027513519112

Lipman, B., Lubell, J., \& Salomon, E. (2012). Housing an aging population: are we prepared. Washington (DC): Center for Housing Policy. Retrieved 10 January, 2019 from http://www.nhc.org/media/files/AgingReport2012.pdf

March, W. L., Officer, A., Cross, M. J., Briggs, M. A., Hoy, D., Riera, L. S., \& Blyth, F. (2015). Musculoskeletal (MSK) health and the impact of MSK disorders in the elderly. In World Health Organization: World Report on Ageing and Health. Geneva: World Health Organization Press.

Max, R. (2018). Life Expectancy. Published online at Our WorldInData.org. Retrieved from https://ourworldindata.org/life-expectancy 18 January 2019.

Moreno, A. C., \& Imamura, M. (2015). What does rehabilitation offer to an ageing population? In World Health Organization: World Report on Ageing and Health. Geneva: World Health Organization Press.

Nash, P. (2015). Ageism. In World Health Organization (P.12): World Report on Ageing and Health. Geneva: World Health Organization Press.

Nigeria Demographic Health Survey. (2013). National Population Commission, Federal Republic of Nigeria, Abuja, Nigeria. ICF Macro Calverton, Maryland, USA. June, 2014.

Ogunniyi, A., \& Aboderin, I. (2007). Hospital-Based Care of Patients with Dementia in Ibadan, Nigeria: Practice, Policy Contexts and Challenges. International Federation on Ageing: Global Ageing: Issues \& Action, 4(3), 45-54.

Ong, P. (2015). Older people as a resource for their own health. In World Health Organization: World Report on Ageing and Health. Geneva: World Health Organization Press.

Pew Research Center. (2014). Attitudes about Aging: a global perspective. Washington (DC). Retrieved 12 January, 2019

from http://www.pewglobal.org/files/2014/01/Pew-Research-Center-Global-Aging-Report-FINAL-January-30-20141 .pdf

Pillemer, K., Burnes, D., Riffin, C., \& Lachs, M. S. (2015). Elder abuse. In World Health Organization: World report on ageing and health. Geneva: World Health Organization Press.

Sadana, R., Blas, E., Budhwani, S., Koller, T., \& Paraje, G. (2015). Healthy ageing: Raising awareness of inequalities, determinants, and whatcould be done to improve health equity. In World Health Organization: World report on ageing and health (pp.25-42). Geneva: World Health Organization Press.

Staudinger, U., Finkelstein, R., Calvo, E., \& Sivaramakrishna, K. (2015). Ageing, work, and health. In World Health Organization: World Report on Ageing and Health. Geneva: World Health Organization Press.

Steves, C. J., Spector, T. D., \& Jackson, S. H. (2012). Ageing, genes, environment and epigenetics: what twin studies tell us now, and in the future. Age Ageing, 41(5), 581-586. https://doi.org/10.1093/ageing/afs097

Stockholm: Swedish National Institute for Public Health. (2006). Healthy ageing: a challenge for Europe. Retrieved 10 January, 2019 from http://www.healthyageing.eu/sites/www.healthyageing.eu/files/resources/Healthy\%20Ageing\%20-\%20A\%20C hallenge\%20for\%20 Europe.pdf

United Nations. (1966). International Covenant on Economic, Social and Cultural Rights. New York: United Nations Retrieved from http://www.ohchr.org/Documents/ProfessionalInterest/cescr.pdf

United Nations. (2002). Political declaration and Madrid international plan of action on ageing. New York: United Nations, 2002. Retrieved 4 January, 2019 from http://www.un.org/en/events/pastevents/pdfs/Madrid_plan.pdf

United Nations. (2012). World population prospects: the 2012 revision. Methodology of the United Nations 
population estimates and projections. New York: United Nations Department of Economic and Social Affairs, Population Division, 2014. Retrieved 4 January, 2019 from http://esa.un.org/wpp/Documentation/pdf/WPP2012_Methodology.pdf

United Nations Department of Economic and Social Affairs/Population Division (un). (2005). World population prospects: The 2004 revision. Retrieved 15 January, 2019 from http://www.esa.un.org/unpp

Uwakwe, R., \& Modebe, I. (2007). Community and Family Care Responses for Persons with Dementia in Eastern Nigeria. International Federation on Ageing: Global Ageing: Issues \& Action, 4(3), 35-44.

Van der geest Sjaak. (2007). Complaining and Not Complaining: Social Strategies of Older People in Kwahu, Ghana. International Federation on Ageing: Global Ageing: Issues \& Action, 4(3), 55-66.

Vasto, S., Scapagnini, G., Bulati, M., Candore, G., Castiglia, L., \& Colonna-Romano, G. et al. (2010). Biomarkes of aging. Front Biosci (Schol Ed), 2(1), 392-402. https://doi.org/10.2741/s72

Velkoff, V. A., \& Kowal, P. R. (2006). Ageing in sub-Saharan Africa: The changing demography of the region. In B. Cohen \& J. Menken (Eds.), Aging in sub-Saharan Africa: Recommendations for furthering research (pp. 55-91). Report of the National Research Council of the National Academies. Washington, DC: National Academies Press. Retrieved from http://books.nap.edu/catalog/11708.html

Wells, J. (2005). Protecting and assisting older people in emergencies. Humanitarian Practice Network (HPN) Network (pp. 53). London: Overseas Development Institute. Retrieved from http://www.reliefweb.int/rw/lib.nsf/db900SID/OCHA-6K4GD3?OpenDocument

World Health Organization. (2002). Active ageing: a policy framework. Geneva: World Health Organization. Retrieved 4 June, 2015 from http://whqlibdoc.who.int/hq/2002/who_nmh_nph_02.8.pdf

World Health Organization. (2015). World report on ageing and health. Retrieved 11 January, 2019 from http://www.who.int/ageing/publications/world-report-2015/en/ 